\title{
Evaluasi Klinis dan Manajemen Kanker Penis di Rumah Sakit Sardjito, Yogyakarta
}

\author{
DENNY ACHMAD PRAYOGA ${ }^{1}$, UNTUNG TRANGGONO² \\ 'Division of Urology, Department of Surgery, Faculty of Medicine, Indonesian University \\ 2Division of Urology, Department of Surgery, Faculty of Medicine, Gajah Mada University \\ Diterima: 10 Agustus 2015; Direview: 12 November 2015; Disetujui: 1 Desember 2015
}

\begin{abstract}
The aim of this study to evaluate clinical and management of penile cancer patients at Sardjito Hospital. Data were collected from medical record of Sardjito Hospital from 2006 - 2013. The clinical factors and therapy were studied from each patient. Correlation between age and stadium of disease were analyzed using Chi-Square Test while the correlation among pathological grade and T, $N$ and $M$ stage were analyzed by using Fisher Test. There are 35 cases of penile cancer with mostly of 40-60 years old man (45.7\%), circumcised (42.9\%), squamos cell type (91.4\%) and perform partial penectomy (45.7\%) followed by chemotherapy (6 patients) and radiotherapy (4 patients). There are no correlation between age and stadium of cancer ( $P>0.05)$, also among pathological grade with $T$, $N$ and $M$ Stage $(P>0.05)$. Penile cancers at Sardjito Hospital mostly found on 40-60 years old, and already developed into advanced disease. The therapy is consist of partial penectomy followed by chemo- radiotherapy.
\end{abstract}

Keyword: penile cancer, epidemiology, clinical profile.

\section{ABSTRAK}

Penelitian ini bertujuan untuk mengevaluasi klinis dan manajemen kanker penis di Rumah Sakit Sardjito. Data dikumpulkan dari rekam medis RS Sardjito tahun 2006-2013. Faktor klinis dan terapi dipelajari dari tiap pasien. Hubungan antara usia dan stadium penyakit dianalisis menggunakan tes Chi-Square, sedangkan hubungan antara tingkatan histopatologi dengan stadium T, N, M dianalisis dengan tes Fisher. Ada 35 kasus kanker penis dengan dominan pada usia 40-60 tahun (45,7\%); telah disunat (42,9\%); tipe karsinoma sel skuamosa (91,4\%); dan dilakukan penektomi parsial (45,7\%) diikuti dengan kemoterapi (6 pasien) serta radioterapi (4 pasien). Tidak ada hubungan antara usia dengan stadium penyakit $(>0,05)$ dan juga antara tingkatan histopatologi dengan stadium T, N, M $(p>0,05)$. Kanker penis di RS Sardjito kebanyakan ditemukan pada usia 40-60 tahun dan telah berkembang menjadi tingkat lanjut. Terapi terdiri dari penektomi parsial diikuti kemo-radioterapi.

Kata Kunci: Kanker penis, epidemiologi, evaluasi klinis

\section{KORESPONDENSI:}

Dr. Deny Achmad Prayoga

Staf Medik Fungsional Urologi RS. Dr. Sardjito Yogyakarta

Email:

denny_prayoga

@yahoo.com

\section{PENDAHULUAN}

\anker penis merupakan kanker pada laki-laki yang jarang terjadi. Insiden kanker I penis di negara Eropa sangat rendah (0.1 0.9/100.000). Sedangkan di Negara Uganda dan Praguay, insiden sebanyak 4.2 - 4.4/100.000 laki-laki. ${ }^{1}$ Data di Asia bervariasi mulai dari $0.04 \%$ di Israel, $0.15 \%$ di Iran hingga $0.2 \%$ di Jepang. ${ }^{2-4}$ Data di Indonesia (RS Hasan Sadikin) pada tahun 1975-1984 didapatkan prevalensi 6\%. ${ }^{5}$ 
Umumnya usia terbanyak ditemukan di Indonesia pada usia 40-50 tahun (26.1\%), dengan mayoritas tidak memiliki riwayat sirkumsisi (47.8\%) dengan letak lesi primer pada glans penis (18.8\%), shaft penis (15.9\%), dan kombinasi glans penis-shaft penis (34.8\%). ${ }^{6}$ Sedangkan di India, mayoritas (72.11\%) ditemukan berusia > 50 tahun, dengan 19.5\% didapatkan riwayat sirkumsisi pada dewasa dan $25.9 \%$ pasien terdapat fimosis. Letak lesi mayoritas pada glans (60\%) dan prepusium (32\%) dan shaft penis pada $8 \%{ }^{7}$

Tatalaksana kanker penis di Indonesia meliputi penektomi baik parsial (33.6\%) maupun total (49.3\%). Tergantung pada lesi primer. Tindakan biopsi saja dikerjakan pada sebagian kecil pasien (14.5\%). Sedangkan diseksi kelenjar getah bening dikerjakan pada sebagian pasien yakni unilateral (5.8\%) dan bilateral (36.2\%). Terapi lain yang dilakukan yakni kemoterapi dilakukan pada lima pasien (7.6\%) sedangkan kombinasi kemoterapi dan radioterapi dikerjakan pada 3 pasien (4.5\%). ${ }^{6}$

Penelitian di Taiwan yang melibatkan 45 pasien, dilakukan pembedahan pada tumor primer meliputi penektomi total atau parsial, sedangkan diseksi kelenjar getah bening dikerjakan pada 19 pasien. Tindakan radioterapi hanya dikerjakan pada 9 pasien. ${ }^{8}$

Sedangkan penelitian di China melakukan kemoterapi neo ajuvan pada 24 pasien kanker penis dengan metastasis ke kelenjar getah bening terfiksir, dengan hanya 15 pasien yang responsif yang dianjutkan penektomi dan diseksi kelenjar getah bening inguinal. Sisanya sebanyak 9 pasien yang tidak responsif dilanjutkan dengan paliatif radioterapi. ${ }^{9}$

Tujuan penelitian ini adalah untuk mengetahui karakteristik dan terapi penderita keganasan penis di RS Sardjito, Yogyakarta.

\section{BAHAN DAN CARA}

Data dikumpulkan dari rekam medik RS Sardjito mulai Januari 2006 hingga Desember 2013. Data yang dikumpulkan berupa usia, suku, status pernikahan, pekerjaan, riwayat sirkumsisi, lokasi kanker, morfologi kanker, tipe kanker, keterlibatan limfonodi inguinal, dan pemeriksaan penunjang. Faktor-faktor patologis yang dipelajari meliputi grade histologis dan staging. Terapi meliputi tindakan terhadap lesi primer, radioterapi, kemoterapi, diseksi kelenjar getah bening, perineostomi, sistostomi. Data dianalisis secara deskriptif dan dilakukan analisa menggunakan SPSS 18 mengenai hubungan antara usia dengan stadium klinis menggunakan test Chi-Square sedangkan hubungan antara grading histopatologi dengan $\mathrm{T}$, $\mathrm{N}$ dan M menggunakan dengan Test Fisher. Penentuan TNM dan staging dilakukan berdasarkan AJCC 2010.

\section{HASIL}

Kanker penis selama 8 tahun ditemukan sebanyak 35 kasus, dengan usia rata-rata $56 \pm 14.4$ tahun, mayoritas bersuku Jawa (91.43\%), Sunda (5.71\%) dan sisanya Papua. Umumnya telah menikah pada 32 pasien (91.4\%) dan bekerja sebagai petani sebanyak 16 pasien (45.7\%). Didapatkan 15 pasien dengan riwayat sirkumsisi (42.9\%), 5 pasien tidak sirkumsisi (14.2\%) dan sisanya tidak ada data sebanyak 15 pasien (42.9\%). (Tabel 1)

Tabel 1: Data deskriptif kanker penis di RS Sardjito periode 2006-2013

\begin{tabular}{|c|c|c|c|}
\hline & Parameter & Frekuensi & Persentase \\
\hline \multirow{4}{*}{ Usia } & $<40$ tahun & 4 & 11,4 \\
\hline & $40-60$ tahun & 16 & 45,7 \\
\hline & $61-80$ tahun & 14 & 40 \\
\hline & $>80$ tahun & 1 & 2,9 \\
\hline \multirow{3}{*}{ Suku } & Jawa & 32 & 91,43 \\
\hline & Suda & 2 & 5,71 \\
\hline & Papua & 1 & 2,86 \\
\hline \multirow{3}{*}{$\begin{array}{c}\text { Status } \\
\text { pernikahan }\end{array}$} & Belum menikah & 1 & 2,9 \\
\hline & Sudah menikah & 32 & 91,4 \\
\hline & Cerai & 2 & 5,7 \\
\hline \multirow{6}{*}{ Pekerjaan } & Petani & 16 & 45,7 \\
\hline & Buruh & 6 & 17,1 \\
\hline & Wiraswasta & 1 & 2,9 \\
\hline & PNS & 2 & 5,7 \\
\hline & Pegawai Swasta & 3 & 8,6 \\
\hline & Tanpa Keterangan & 7 & 20 \\
\hline \multirow{3}{*}{ Sirkumsisi } & Ya & 15 & 42,9 \\
\hline & Tidak & 5 & 14,2 \\
\hline & Tanpa Keterangan & 15 & 42,9 \\
\hline
\end{tabular}

Berdasarkan pemeriksaan fisik, mayoritas letak lesi terdapat pada shaft penis $(68.4 \%)$ dengan diameter $5-10 \mathrm{~cm}$ sebanyak 14 kasus (40\%), berbentuk ulserasi sebanyak 14 kasus (40\%), berjumlah satu buah sebanyak 29 kasus (82.9\%). Limfonodi inguinal teraba pada 12 kasus (34.3\%) dengan letak bilateral pada 9 kasus (75\%). 
Pada hasil pemeriksaan patologi anatomi, diketahui bahwa 32 kasus didapatkan jenis sel skuamosa (91.4 $\%$ ), sedangkan sisanya berupa tipe verukosa (8.6 \%). (Tabel 2)

Tabel 2: Karakteristik klinis kanker penis di RS Sardjito 2006-2013

\begin{tabular}{|c|c|c|c|}
\hline & Parameter & Frekuensi & Persentase \\
\hline & Letak & & \\
\hline & Glans Penis & 11 & 31,4 \\
\hline & Shaft Penis & 24 & 68,4 \\
\hline & Diameter & & \\
\hline & $<5 \mathrm{~cm}$ & 12 & 34,3 \\
\hline & $5.10 \mathrm{~cm}$ & 14 & 40 \\
\hline & $>10 \mathrm{~cm}$ & 9 & 25,7 \\
\hline & Bentuk & & \\
\hline \multirow[t]{13}{*}{ Lesi } & Papiler & 9 & 25,7 \\
\hline & Noduler & 3 & 8,6 \\
\hline & Ulserasi & 14 & 40 \\
\hline & Lainnya & 1 & 2,9 \\
\hline & Tidak disebutkan & 8 & 22,9 \\
\hline & Jumlah & & \\
\hline & Satu & 29 & 82,9 \\
\hline & Multiple & 2 & 5,7 \\
\hline & Tidak disebutkan & 4 & 11,4 \\
\hline & Palpasi & & \\
\hline & Teraba & 12 & 34,3 \\
\hline & Tidak teraba & 10 & 28,6 \\
\hline & Tidak ada data & 13 & 37,1 \\
\hline \multirow[t]{5}{*}{ Limfonodi } & Letak & & \\
\hline & Kanan & 0 & 0 \\
\hline & Kiri & 1 & 8,4 \\
\hline & Bilateral & 9 & 75 \\
\hline & Tidak disebutkan & 2 & 16,6 \\
\hline \multirow{2}{*}{ Hasil PA } & Skuamosa & 32 & 91,4 \\
\hline & Verukosa & 3 & 8,6 \\
\hline
\end{tabular}

Berdasarkan evaluasi klinis dan pemeriksaan penunjang seperti Patologi Anatomi, USG Abdomen, Rontgen Thorax serta CT-Scan Abdomen didapatkan terbanyak staging T3 sebanyak 16 kasus (45.7\%), staging N0 sebanyak 14 kasus (40\%), staging M1 sebanyak 1 kasus (5\%) dan grading histopatologi Gl (diferensiasi baik) sebanyak 24 kasus (68.6\%). (Tabel 3)
Tabel 3: Staging dan Grading kanker penis di RS Sardjito 2006-2013 Berdasarkan AJCC 2010

\begin{tabular}{|c|c|c|c|}
\hline & Parameter & Frekuensi & Persentase \\
\hline \multirow{5}{*}{$\mathrm{T}$} & $\mathrm{Tx}$ & 0 & 0 \\
\hline & $\mathrm{T} 1$ & 0 & 0 \\
\hline & T2 & 15 & 42,9 \\
\hline & T3 & 16 & 45,7 \\
\hline & T4 & 4 & 11,4 \\
\hline \multirow{5}{*}{ N } & $\mathrm{Nx}$ & 8 & 22,9 \\
\hline & NO & 14 & 40 \\
\hline & N1 & 1 & 2,9 \\
\hline & N2 & 10 & 28,6 \\
\hline & N3 & 2 & 5,7 \\
\hline \multirow{3}{*}{ M } & $M x$ & 26 & 74,3 \\
\hline & MO & 8 & 22,9 \\
\hline & M1 & 1 & 2,9 \\
\hline \multirow{3}{*}{ G } & G1 & 24 & 68,6 \\
\hline & G2 & 8 & 22,9 \\
\hline & G3 & 3 & 8,6 \\
\hline
\end{tabular}

Berdasarkan Stadium kinis, tidak didapatkan pasien pada stadium awal, sedangkan stadium II terdapat 17 pasien (48.6\%), III A sebanyak 4 pasien (11.4\%), III B sebanyak 8 pasien (22.9\%) serta Stadium IV sebanyak 6 pasien (17.1\%). (Tabel 4)

Tabel 4: Stadium klinis kanker penis di RS Sardjito periode 2006-2013 Berdasarkan AJCC 2010

\begin{tabular}{ccc}
\hline Stadium & Frekuensi & Persentase \\
\hline 0 & 0 & 0 \\
I & 0 & 0 \\
\hline II & 17 & 48,6 \\
III A & 4 & 11,4 \\
III B & 8 & 22,9 \\
\hline IV & 6 & 17,1 \\
\hline
\end{tabular}

Tindakan primer pada berupa biopsi saja sebanyak 5 pasien (14.3\%), parsial penektomi sebanyak 16 pasien (45.7\%) dan total penektomi sebanyak 14 pasien (40\%). Operasi lain yang juga dikerjakan pada pasien ini meliputi perineostomi pada 3 pasien (8.57\%), sistostomi pada 1 pasien $(2.85 \%)$ dan reseksi KGB Inguinal pada 3 pasien (8.57\%). Pasca tindakan pembedahan penektomi, terdapat 6 pasien yang mendapatkan terapi berupa kemoterapi (17.14\%) dan 4 pasien mendapatkan terapi berupa radioterapi (11.43\%). (Tabel 5) 
Tabel 5: Manajemen pada kanker penis di RS Sardjito periode 2006-2013

\begin{tabular}{llcc}
\hline & \multicolumn{1}{c}{ Stadium } & Frekuensi & Persentase \\
\hline \multirow{4}{*}{ Tindakan primer } & Biopsi saja & 5 & 14,3 \\
& Parsial Penektomi & 16 & 45,7 \\
& Total Penektomi & 14 & 40 \\
\hline \multirow{3}{*}{ Tindakan sekunder } & Perineostomi & 3 & 42,8 \\
& Sistostomi & 1 & 14,4 \\
& Reseksi KGB & 3 & 42,8 \\
\hline \multirow{2}{*}{ Tindakan lainnya } & Inguinal & & 17,14 \\
& Kemoterapi & 6 & 11,43 \\
\hline
\end{tabular}

Meskipun pasien kanker penis yang berobat ke RS Sardjito, umumnya sudah masuk stadium lanjut, namun tidak didapatkan hubungan antara usia dengan stadium klinis $(\mathrm{p}=0.092)$. (Tabel 6)

\section{Tabel 6: Hubungan usia dengan stadium klinis}

\begin{tabular}{lccc}
\hline & \multicolumn{2}{c}{ Stadium Klinis } & Chi-Square \\
\cline { 2 - 3 } & Stadium 0-2 & Stadium 3-4 & Test \\
\hline Usia $<60$ tahun & 7 & 13 & $p=0,092$ \\
Usia $>60$ tahun & 10 & 5 & \\
\hline
\end{tabular}

Demikian pula grade histopatologi yang ditemukan umumnya berupa derajat 1 atau 2, namun tidak ditemukan hubungan antara garde Histopatologi dengan Derajat T, $\mathrm{N}$ maupun $\mathrm{M}$ (nilai $\mathrm{p}>0.005$ ). (Tabel 7).

Tabel 7: Hubungan grade hispatologi dengan derajat T, N, dan M

\begin{tabular}{ccccccc}
\hline & \multicolumn{2}{c}{ Derajat T } & \multicolumn{3}{c}{ Derajat N } & \multicolumn{3}{c}{ Derajat M } \\
\cline { 2 - 7 } & T 0-2 & T 3-4 & N0 & N 1-3 & M0 & M1 \\
\hline G1 & 10 & 14 & 9 & 15 & 23 & 1 \\
G2 + G3 & 5 & 6 & 6 & 5 & 11 & 3 \\
\hline $\begin{array}{c}\text { Fisher } \\
\text { Exact Test }\end{array}$ & $\mathrm{p}=1,00$ & $\mathrm{p}=0,467$ & $\mathrm{p}=1,000$ \\
\hline
\end{tabular}

\section{DISKUSI}

\section{Insidensi dan Epidemiologi}

Angka kejadian keganasan penis di Indonesia secara nasional belum pernah diketahui. Namun data secara lokal di RS Hasan Sadikin menyebutkan sekitar 6\% dari keseluruhan keganasan urologi. ${ }^{5}$ Data dari RS Cipto Mangunkusumo dan RS Dharmais menyebutkan adanya 69 kasus dalam kurun waktu
11 tahun (6.3 kasus per tahun). ${ }^{6}$ Pada penelitian ini didapatkan 4.3 kasus per tahun. Hal ini bisa dikarenakan perbedaan geografis dan pengetahuan pasien akan kanker.

Usia penderita keganasan penis pada penelitian ini dengan rata-rata $56.06 \pm 14.43$ tahun dengan usia termuda 28 tahun dan tertua 82 tahun. Hal ini berbeda dengan penelitian di Jakarta yang menyebutkan median 48.75 tahun dengan usia termuda 23 tahun dan tertua 85 tahun. $^{6}$

Hasil penelitian ini menunjukkan Karsinoma Sel Skuamosa sebanyak 32 kasus (91.4\%) sedangkan jenis Verrucous Carcinoma dijumpai pada 3 pasien (8.6\%). Insidensi penyakit ini yang juga disebut sebagai giant condyloma acuminatum atau BuschkeLowenstein kanker tidak diketahui, tetapi mungkin lebih tinggi dari yang dilaporkan dinyatakan sebagai low-grade squamous carcinoma penis. Sedangkan penelitian di Jakarta menyebutkan jenis karsinoma sel skuamosa sebanyak $86.9 \%$ diikuti oleh Verrucous Carcinoma dan Leiomyosarcoma. ${ }^{6}$

Sirkumsisi merupakan tindakan pencegahan timbulnya kanker penis. Sirkumsisi yang dilakukan pada saat anak-anak atau remaja bersifat protektif dengan ods rasio 0.33 (95\% CI 0.13-0.83). Namun resiko mendapat kanker penis yang invasif meningkat diantara pasien yang dilakukan sirkumsisi saat dewasa. ${ }^{10}$ Pada penelitian ini, hanya satu orang yang diketahui dilakukan sirkumsisi, sedangkan yang lainnya tidak didapatkan keterangan. Demikian pula tidak didapatkan keterangan usia saat sirkumsisi. Sedangkan data di Jakarta menyebutkan hanya 30 pasien (44.9\%) yang dilakukan sirkumsisi, 33 pasien (47.8\%) tidak dilakukan sirkumsisi dan 6 pasien tidak ada keterangan (8.7\%). ${ }^{6}$ Di India dari sebanyak 54 pasien dengan kanker penis, hanya 10 pasien (19.5\%) yang terdapat riwayat sirkumsisi pada saat dewasa, 14 pasien (25.9\%) terdapat fimosis, sisanya tidak ada keterangan. ${ }^{7}$

\section{Tindakan Terhadap Lesi Primer}

European Association of Urology (EAU) telah membuat suatu panduan untuk penanganan Kanker Penis disesuaikan dengan Kategori Staging $\mathrm{T}$ dan juga staging N. Demikian pula National Comprehensive Cancer Network juga membuat panduan untuk penanganan Kanker Penis disesuaikan dengan Kategori Staging T, N maupun M. ${ }^{11}$

Penanganan pasien kanker penis dalam penelitian ini mengacu kepada panduan dari European Association of Urology (EAU) yakni melakukan parsial penektomi pada T2, sedangkan pada T3 dilakukan total penektomi dan perineostomi. ${ }^{11}$ Pada penelitian 
kami, pada staging T2 didapatkan 15 pasien yang mana 10 pasien (66.7\%) dilakukan parsial penektomi, 3 pasien dilakukan total penektomi (20\%) dan 2 orang lainnya tidak dilakukan tindakan (13.3\%) karena pasien menolak. Pada Staging T3 didapatkan 5 pasien (31.3\%) dilakukan parsial penektomi, 9 pasien (56.3\%) dilakukan total penektomi dan 2 pasien (12.5\%) menolak tindakan operasi. Selain itu juga dilakukan perineostomi pada 3 kasus (18.8\%) dan sistostomi pada 1 kasus (6.3\%) serta 1 orang dilakukan reseksi KGB inguinal (6.3\%). Sedangkan Staging T4 didapatkan 1 pasien dilakukan parsial penektomi, 2 pasien dilakukan total penektomi dan 1 pasien tidak dilakukan operasi karena menolak. Adapun perbedaan penanganan ini dikarenakan pemeriksaan Frozen Section pada saat operasi, dimana bila ditemukan batas proksimal dari insisi dinyatakan bebas kanker, maka diputuskan untuk parsial ataupun total penektomi.

\section{Karakteristik Patologi}

Pemeriksaan patologi anatomi, merupakan pemeriksaan baku emas dalam penegakkan diagnosis kanker penis. Dalam pemeriksaan ini, dapat ditentukan jenis sel, derajat patologi, keterlibatan corpora cavernosa, corpora spongiosum, limfonodi inguinal hingga penentuan bebas kanker pada batas proksimal insisi penektomi. ${ }^{11}$

Karsinoma sel skuamosa memegang 48-65\% dari keganasan penis sedangkan sisanya meliputi tipe basaloid, verukosa, sarkomatoid dan adenoskuamosa." Pada penelitian ini, didapatkan karsinoma sel skuamosa pada 32 kasus (91.4\%) sedangkan sisanya berupa verukosa pada 3 kasus (8.6\%).

Grade histopatologi dibagi menjadi derajat satuberdiferensiasi baik, derajat dua-berdiferensiasi sedang, derajat tiga-berdiferensiasi buruk dan derajat empat-tidak berdiferensiasi. ${ }^{11}$ Pada penelitian kami, didapatkan 24 pasien digolongkan sebagai derajat 1 (68.6\%), 8 pasien pada derajat 2 (22.9\%) dan 3 orang lainnya digolongkan kepada derajat $3(8.6 \%)$.

Grade kanker juga berhubungan dengan angka ketahanan hidup karena memberikan informasi yang prediktif terhadap kemungkinan adanya metastasis kelenjar getah bening. ${ }^{6}$ Namun pada penelitian kami tidak didapatkan hubungan antara grade kanker dengan derajat $\mathrm{T}, \mathrm{N}$ maupun $\mathrm{M}$.

\section{Diseksi Kelenjar Getah Bening}

Penanganan keterlibatan kelenjar getah bening regional berkaitan dengan ketahanan hidup. EAU Guideline memberikan panduan berupa surveilans pada pasien dengan kelenjar getah bening inguinal yang normal dengan kanker derajat rendah (pTa/ pTis). Sedangkan pada tumor derajat sedang maupun tinggi namun tidak teraba kelenjar getah bening, dapat dilakukan dua prosedur diagnostik invasif yakni diseksi kelenjar getah bening inguinal modifikasi dan biopsi dinamik kelenjar getah bening sentinel. Pada kelenjar getah bening inguinal yang teraba, diseksi radikal kelenjar getah bening inguinal diindikasikan.Sedangkan bila terdapat dua atau lebih kelenjar getah bening yang postif atau bila didapatkan satu kelenjar dengan ekstensi ekstra kapsular (pN3), diseksi kelenjar getah bening pelvis ipsilateral diindikasikan. ${ }^{11}$

Pada penelitian ini, didapatkan 1 pasien pada stadium N1 (2.9\%), 10 pasien pada stadium N2 (28.6\%) dan 2 pasien pada stadium N3 (5.7\%). Namun tindakan limfadenektomi hanya dikerjakan pada 3 pasien saja, sedangkan sisanya dilakukan kemoterapi ( 5 pasien) maupun radioterapi ( 3 pasien). Sedangkan penelitian di Jakarta menyebutkan diseksi kelenjar getah bening inguinal bilateral dilakukan pada 25 pasien $(36.2 \%)$ dan unilateral pada 4 pasien $(5.8 \%){ }^{6}$

\section{Staging Keganasan Penis}

European Association of Urology dan National Comprehensive Cancer Network menggunakan sistem staging keganasan penis berdasarkan AJCC Cancer Staging tahun 2010, dimana penderita keganasan penis dikeompokkan menurut $\mathrm{T}$ (Kanker), N (Nodus) dan $\mathrm{M}$ (metastasis), kemudian dikelompokkan lagi dalam stadium 0 , stadium 1, stadium 2, stadium 3A, Stadium 3B dan stadium $4 .{ }^{11}$

Pada penelitian ini, didapatkan 15 pasien digolongkan kepada T2 (42.9\%), 16 pasien pada T3 (45.7\%) dan 4 pasien pada T4 (11.4\%). Sedangkan pada Staging N, didapatkan 8 pasien digolongkan sebagai Nx (22.9\%), 14 pasien pada N0 $(40 \%), 1$ pasien pada N1 (2.9\%), 10 pasien pada N2 (28.6\%) dan 2 pasien pada N3 (5.7\%). Penyebaran ke tempat lain (metastasis) didapatkan pada 1 pasien $(2.9 \%)$, 8 pasien tidak memiliki metastasis (22.9\%) sedangkan 26 pasien digolongkan pada Mx (74.3\%). Pada penelitian serupa di Jakarta, diketahui sebagian besar penderita dijumpai pada Stage $\mathrm{T} 1$ dan T2 (63.9\%), stage N1-3 (49.3\%) dan hanya 6.3\% dalam stage M1. ${ }^{6}$

Berdasarkan stadium klinis, didapatkan 17 pasien pada stadium 2 (48.6\%), 4 pasien pada stadium 3A (11.4\%), 8 pasien pada stadium 3B (22.9\%) dan 6 pasien pada stadium 4 (17.1\%). Sedangkan penelitian di Jakarta menyebutkan mayoritas pasien pada 
stadium 4 (29\%), stadium 3 (20\%), stadium 2 (17.7\%) dan sadium 1 (19.4\%). ${ }^{6}$

\section{Terapi Lain}

Berdasarkan EAU Guidelines, pemberian Radioterapi diberikan pada Lesi T1-T2 dengan diameter $<4 \mathrm{~cm}$. Sedangkan pemberian radioterapi pada keterlibatan kelenjar getah bening pada kanker penis secara umum tidak direkomendasikan karena kurangnya bukti. Pada kasus yang tidak dapat direseksi dengan operasi, pemberian radioterapi untuk kelenjar getah bening inguinal bersifat paliatif."

Pemberian kemoterapi topical seperto imiquimod atau 5 Fluorouracil (5-FU) diberikan pada karsinoma in situ. Sedangkan pada pasien dengan pN2/pN3, kemoterapi ajuvan direkomendasikan. Regimen yang diberikan dapat berupa VBM ( Vincristin, Bleomycin dan metotreksat), kombinasi cisplastin dan 5-FU atau sediaan berbasis taxane. Kemoterapi neo ajuvan diberikan pada kelenjar getah bening inguinal yang terfiksir (cN3). ${ }^{11}$

Pada penelitian ini terdapat 5 pasien yang dilakukan kemoterapi saja, 3 pasien yang dilakukan radioterapi saja dan 1 pasien yang dilakukan kemoterapi dan radioterapi. Adapun pemberian kemoterapi berupa Cisplastin (1 pasien), Carboplastin (1 Pasien) dan kombinasi Pacitaxel dan Carboplastin (1 orang), sisanya tidak disebukan regimen kemoterapi yang diberikan. Radioterapi diberikan kepada 4 pasien dengan dosis 50-54 Gray.

\section{KESIMPULAN}

Selama periode 8 tahun di RS Sardjito dijumpai 35 kasus pasien dengan kanker penis. Karakteristik klinis tersering kanker penis di RS Sardjito adalah usia 40-60 tahun, bersuku Jawa, sudah menikah dengan profesi sebagai petani dan telah menjalani sirkumsisi. Letak lesi primer terutama ada shaft penis, berjumlah satu buah dengan tipe ulseratif dengan diameter 5-10 cm dimana limfonodi inguinal teraba bilateral. Berdasarkan system TNM, kebanyakan kasus pada stadium II. Tindakan operasi berupa penektomi parsial. Pasca operasi sebanyak 6 pasien menjalani kemoterapi dan 4 pasien menalani radioterapi. Berdasarkan jenis histopatologi, terbanyak dengan kanker sel skuamosa derajat satu.
Staging terbanyak adalah T3 (45.7\%), N2 (28.6\%) dan Mx (74.3\%). Tidak dijumpai hubungan yang bermakna antara usia dengan stadium klinis. Demikian pula tidak ada hubungan yang bermakna antara grade histopatologi dengan parameter klinis $\mathrm{T}, \mathrm{N}$ maupun $\mathrm{M}$.

\section{DAFTAR PUSTAKA}

1. Minhas S, Manseck A, Watya S, Hegarty PK. Penile CancerPrevention and Premalignant Conditions. Urology.2010; 76 (Suppl 2A): S24-S35.

2. Graffland NM, Verhoeven RHA, Coeberg JW, Horenblas S. Incidence trends and survival of penile squamous cell carcinoma in the Netherlands. Int J Cancer. 2010; 128: 426-32.

3. Akbari EM, Hosseini SJ, Rezaee A, Hosseini MM, Rezaee I, Sheikhvatan $M$. Incidence of Genitourinary Cancer in the Islamic Republic of Iran: A Survey in 2005. Asian Pacific J Cancer Prev. 2008; 9:549-52.

4. Marugame T, Katanoda K, Matsuda T, Hirabayashi Y, Kamo K, Ajiki W, et al. The Japan Cancer Surveillance Report: Incidence of Childhood, Bone, Penis and Testis Cancers. Jpn J Clin Oncol. 2007;37(4): 319-23.

5. Sugandi S. Referral Pattern of Urological Malignancy in Indonesia.Br J Urol.1989;63(1):1-3.

6. Tranggono U, Umbas R. Karakteristik dan Terapi Penderita Keganasan Penis di RS Cipto Mangunkusumo dan RS Kanker Dharmais. Indonesian Journal of Cancer. 2008; 2: 45-50.

7. Pahwa M, Girotra M, Rautela A, Abrahim R. Penile Cancer in India: A Clinicoepidemiological Study. Gulf J Oncol. 2012;12:7-10.

8. Chen M, Chen W, Wu C, Chuang C, Ng K, Chang J. Contemporary management of penile cancer including surgery and adjuvant radiotherapy: an experience in Taiwan. World J Urol. 2004;22:6066.

9. Zou B, Han Z, Wang Z, Bian J, Xu J, Wang H. Neoadjuvant therapy combined with a BMP regimen for treating penile cancer patients with lymph node metastasis : a retrospective study in China. J Cancer Res Clin Oncol. 2014;140(10):1733

10. Larke NL, Thomas SL, Silva I, Weiss HA. Male circumcision and penile cancer: a systematic review and meta-analysis. Cancer Causes Control. 2011; 22:1097-1110

11. Hakenberg OW, Comperat EM, Minhas S, Necchi A, Protzel C, Watkin N. EAU Guidelines n Penile Cancer: 2014 Update. Eur Urol. 2015 Jan;67(1):142-50 